\title{
LUZES E SOMBRAS NA OBRA DE KAJII MOTOJIRÔ \\ LIGHTS AND SHADOWS IN KAJII MOTOJIRÔ'S WRITTINGS ${ }^{1}$
}

Karen Kazue Kawana ${ }^{2}$

Resumo: Kajii Motojirô (1901-1932) é um escritor de curta carreira literária, ela durou apenas sete anos, terminando com sua morte precoce por tuberculose. A doença é presença constante nos vinte contos reunidos na coletânea Remon (O Limão, 1931). Luzes, sombras e escuridão também são temas frequentes e que estão intimamente ligados à sua condição física e ao seu estado de espírito. Este artigo trata das nuances que essas relações trazem às suas obras.

Palavras-chave: Kajii Motojirô; Literatura Japonesa; Luzes; Sombras; Escuridão.

Abstract: Kajii Motojirô (1901-1932) is a writer with a short literary career, it lasted only seven years and ended with his early death by tuberculosis. The disease is a constant presence in the twenty short stories compiled in Remon (Lemon, 1931). Lights, shadows and darkness are also frequent subjects in his texts and they are intimately tied to his physical condition and mental state. This article is about the undertones that these relations bring to his literary work.

Keywords: Kajii Motojirô; Japanese Literature; Lights; Shadows; Darkness.

Kajii Motojirô (1901-1932) nasceu em Osaka em uma família abastada e morreu de tuberculose aos trinta e um anos. Sua curta carreira literária durou sete anos. Isso não o coloca no panteão dos grandes escritores japoneses, mas sua prosa poética, com imagens vívidas, lhe renderam o reconhecimento póstumo. Seu legado literário é constituído de vinte contos compilados na coletânea Remon ( $O$ Limão, 1931) e outros textos inacabados. Kajii passou a receber atenção da comunidade literária após sua morte devido à contribuição de amigos e, hoje, o conto que dá nome à coletânea é praticamente leitura obrigatória no ensino secundário no Japão.

1 Article received and accepted in 2019.

2 Doutora pelo Departamento de Filosofia do Instituto de Filosofia e Ciências Humanas da Universidade Estadual de Campinas, Campinas, Brasil; kawanakk@uol.com.br; (ORCID iD: https://orcid. org/0000-0003-1030-5070). 
Uma das características marcantes de seus textos é o papel de destaque conferido à escuridão, às sombras e à noite. Esses elementos transformam o interior das florestas e as caminhadas noturnas que descreve em experiências feéricas e inquietantes. Sua relação com a escuridão é de atração e temor. Ela encerra mistérios que não consegue desnudar, evoca sentimentos em conflito em seu interior. Diagnosticado com tuberculose aos dezenove anos, sua escrita é marcada pela luta diária com a doença e pela consciência de que seus dias estão contados. Este artigo trata das relações entre as imagens empregadas pelo autor em seus textos, sua preferência pela escuridão, e as inquietações que trazem à tona. Para nós, elas dão profundidade à sua escrita.

Apesar de ter iniciado os estudos para se tornar um engenheiro, Kajii logo perdeu o interesse pelo curso para se voltar para a música e a literatura, lendo, com especial interesse, as obras de Sôseki Natsume (1867-1916) e Tanizaki Jun'ichiro (1886-1965).

Durante essa época, ele se entregou a uma vida de decadência, bebia, brigava, fugia das pensões sem pagar contas e pensava em se matar. Apesar da existência conturbada, ele lia com avidez e se interessava pelo universo literário, que se expandia cada vez mais para englobar os autores do grupo Shirakaba - como Mushakôji Saneatsu (18851976), Shiga Naoya (1883-1971) e Arishima Takeo (1878-1923) —; ideias socialistas e cristãs; além de autores europeus como Tolstói, Dostoiévski, Nietzsche e Strindberg (MOY, 1977). Seu interesse pela literatura o levava a sonhar em ir a Tóquio, mudar de vida e se dedicar à escrita. Assim, após a formatura, em 1924, ele entra no departamento de literatura da Universidade Imperial de Tóquio e, junto com alguns colegas, publica a revista Aozora (Céu Azul, 1925-1927), na qual publica seus textos.

No entanto, a deterioração da saúde e a piora da condição pulmonar acabam por fazer com que ele desista de concluir o curso. Ele vai a Yugashima, na península de Izu, para convalescer e aí permanece por dezesseis meses. É em Yugashima que Kajii encontra Kawabata Yasunari (1899-1972), autor que admira e com quem estabelece uma relação de amizade, e onde continua a escrever. Com o fim da Aozora, ele passa a publicar seus textos em outras revistas. Porém, cada vez mais enfermo, ele retorna a Osaka em 1928 para viver com sua família e morre sob os cuidados da mãe.

Seu último conto é Nonki na Kanja (O paciente despreocupado, 1932), publicado na prestigiosa revista Chûo Kôron. Nele, Kajii relata suas experiências e observações sobre como a tuberculose afeta o cotidiano das pessoas comuns. O crítico literário Kobayashi Hideo (1902-1983), que lera e apreciara a coletânea Remon, elogia o conto. Porém, Kajii morre em março de 1932 sem saber que sua escrita começava a ser reconhecida. Suas obras completas foram publicadas algum tempo depois com a ajuda de Kawabata. No entanto, sua reputação como escritor se estabelece apenas após a Segunda Guerra Mundial.

Kajii é um autor de estilo poético no qual predominam descrições nas quais o inusitado e o grotesco se misturam com o ordinário e o belo. A escuridão se torna cada vez mais presente à medida que a doença avança, mas, longe de ser um reflexo de sua dor e desespero, ela se torna o motor de sua obra, se o seu estado de saúde o confinava 
em quartos, a paisagem que contemplava da janela se transformava na tela em constante transformação que observava com curiosidade. A paisagem noturna era uma de suas favoritas. Ao comentar o conto Sôkyû (Céu Azul, 1928), o escritor Mishima Yukio (1925-1970) escreve: "enquanto há alguns escritores que possuem corpos saudáveis e espíritos doentes, também há escritores como Kajii Motojirô, que estão doentes, mas cujos espíritos são saudáveis e fortes." (MISHIMA apud MORRISON, 2014, p. 187, tradução nossa) $)^{3}$.

Kajii faz parte do grupo de escritores japoneses que vê a literatura como uma obra de arte, um esforço criativo que está além da imitação do real. Ele pode ser classificado como fazendo parte da escola Neossensualista (Shinkankakuha), de vertente modernista ativa nos anos 20, mesmo sem fazer parte ou ser mencionado pelos membros da Bungei Jidai, a revista produzida por esse grupo. Ele é composto por escritores como Yokomitsu Riichi (1898-1947), Kawabata Yasunari, Kishida Kunio (1890-1954), Nakagawa Yoichi (1897-1994), entre outros. Os neossensualistas valorizam imagens e descrições e é por meio delas que o estado subjetivo dos personagens se revela.

Segundo Moy (1977), as obras de Kajii podem ser divididas em três períodos. O primeiro começaria com a publicação de Remon e iria até Kako (O passado, 1926). Nessa fase, a realidade é contraposta à ideia de decadência, o frescor do limão dá lugar à ideia de destruição da livraria Maruzen, como em Remon; e as lembranças de um passado luminoso e despreocupado são substituídas por um sentimento de perda, o bairro onde o protagonista foi feliz não existe mais e ele não consegue encontrar as referências de seu passado, como em Kako. A passagem do tempo e as mudanças que afetam objetos e pessoas expressam a transitoriedade das coisas. O ser humano não é mais do que alguém que está de passagem, ele é um viajante, como vários de seus personagens repetem com frequência.

O segundo período da escrita de Kajii se iniciaria com $K$ no Shôten (A Ascensão de K, 1926), excluindo seu último conto, Nonki na Kanja (O Paciente despreocupado, 1932). As descrições são dominantes nesse período. Elas são impactantes e vívidas, quase alucinações, visões de um homem solitário, quase um pária devido à doença. Os protagonistas deixam a imaginação vagar enquanto contemplam os objetos ao redor e o tema da escuridão se torna ainda mais presente. Muitos contos foram escritos durante a estadia do autor em Yugashima, local onde convalescia.

O terceiro período é o embrião de algo que poderia ter sido, já que Kajii morreu pouco depois de Nonki na Kanja ser publicado. Este trata do ser humano no contexto da sociedade em que se insere e revela uma nova direção na obra de Kajii. Se, antes, os textos trazem um protagonista isolado e entregue a suas divagações, em Nonki na $K a n j a$, o autor revela uma tendência a observar a sociedade quando narra os problemas vividos pelas pessoas afetadas pela tuberculose: o desespero pela busca de tratamentos alternativos e pouco eficazes, as pessoas que se aproveitam da vulnerabilidade dos

3 Todas as traduções do japonês e do inglês para o português são nossas. 
doentes, a solidão e impotência diante da morte, a penúria e as dificuldades cotidianas dos tísicos das camadas mais pobres.

Apesar de os textos que seguiam o gênero da Escrita do $\mathrm{Eu}^{4}$ estarem em voga no Japão na primeira metade do século XX e de Kajii descrever aquilo que via com as cores de sua sensibilidade, acreditamos que não seja possível classificá-lo como um escritor desse gênero. Uma boa analogia talvez seja a de um pintor que não coloca a si mesmo em suas telas, ele apenas as transforma e cristaliza de acordo com suas emoções e percepções, em particular, com as cores da angústia e ansiedade que o confronto com a realidade lhe despertava, sua impotência diante da vida, sentimentos presentes em vários de seus textos, como em Remon:

Uma massa indefinida e ominosa comprimia meu coração sem cessar. Não sabia dizer se era exasperação ou repulsa. Lembrava a ressaca após uma noite de bebedeira. Bebedores frequentes estão sujeitos a sofrerem de ressaca. E era como me sentia. Para azar meu. O catarro nos pulmões e o colapso nervoso não eram tão ruins. Nem as dívidas que ardiam sobre minhas costas. O que era ruim era essa massa ominosa. Já não tinha paciência para ouvir as músicas de que gostava antes, nem para ler sequer um verso de um belo poema. Mesmo quando era convidado a ouvir música no gramofone na casa de alguém, ficava com vontade de me levantar logo depois dos dois ou três compassos iniciais. Havia alguma coisa que me deixava inquieto e me fazia vagar pelas ruas continuamente. (KAJII, 1974, tradução nossa) $)^{5}$

Os objetos e imagens surgem filtrados por seu estado mental e são transformados por sua imaginação. Interior e exterior se fundem e não é possível separá-los, assim, um inofensivo limão comprado em uma frutaria é capaz de proporcionar um sentimento de indescritível frescor e felicidade e, no momento seguinte, ser depositado entre os livros de arte como uma bomba que, na imaginação do protagonista, logo explodirá no interior da livraria Maruzen.

Em um Japão que procura se modernizar e deixar uma imagem de país atrasado para se equiparar às potências ocidentais, não causa estranhamento que as pessoas se sintam perdidas em um ambiente em mutação, no qual há uma perda de referências porque o "tradicional" é considerado ultrapassado e precisa ser substituído por valores e ideias novas. Kajii é fruto dessa época e seus textos expressam esse sentimento de

4 Também conhecido como Watakushi shôsetsu ou Shishôsetsu e traduzido como Romance do Eu ou Escrita do $\mathrm{Eu}$ (nossa preferência). O texto escrito em primeira pessoa, no qual há elementos autobiográficos, é característico desse gênero. Ver Nagae, N. H. De Katai a Dazai: Apontamentos para uma morfologia do Romance do Eu. Tese de Doutorado, Universidade de São Paulo, 2006.

5 Como a referência empregada para as citações das obras do autor é da versão em html do site https:// www.aozora.gr.jp/, não temos como especificar o número de página. 
alienação. No entanto, ele começa a se voltar para temas de ordem social de forma mais explícita apenas em Nonki na Kanja. Nos dois períodos anteriores de sua escrita, seus temas são mais intimistas, talvez um reflexo de sua própria juventude.

A doença deteriora seu corpo, mas ainda há beleza no exterior e isso o reconforta. O contraste entre grotesco e belo, luzes e sombras, está no cerne de sua obra:

Por alguma razão, objetos de beleza decadente exerciam grande atração sobre mim nessa época. Por exemplo, apreciava as ruas de quarteirões dilapidados, não as ruas principais que me recebiam com frieza, mas as vielas que revelavam sua intimidade: as roupas sujas penduradas nos varais e o lixo espalhado pelo chão; os interiores dos cômodos imundos que entrevia quando passava diante das casas. Quarteirões com ar de que retornariam ao pó, corroídos pelas intempéries, cujas paredes de taipa desabavam e as casas começavam a se inclinar, nos quais apenas as plantas cresciam com vigor. Onde, por vezes, era surpreendido por girassóis e cannas floridos. (KAJII, 1974, tradução nossa)

A decadência exterior se assemelha à sua deterioração física, mas, ao encontrar beleza mesmo em lugares inusitados, ele é capaz de fazer as pazes consigo mesmo ao compreender que é parte da natureza, onde destruição e criação são processos constantes e na qual não há lugar para juízos de valor, não há bem ou mal, justiça ou injustiça. $\mathrm{O}$ que ocorre com seu corpo faz parte dos processos naturais e inexoráveis, ao considerar sua doença dessa forma, ele consegue se distanciar e se torna um observador imparcial de sua deterioração física.

Seus textos questionam as ideias de vida e morte, especialmente sua própria mortalidade. Ele era um jovem escritor cheio de ambições para quem se torna óbvio que sucumbirá à tuberculose, destino que não era inusitado na época. Kajii viu vários membros de sua família morrerem da mesma doença. Dois irmãos mais jovens e uma irmã, enquanto o irmão mais velho teve que se submeter a cirurgias pulmonares. A tuberculose era uma doença cruel que acometia a população independente de classe social.

A visão da escuridão, dominante e constante no período em que convalescia em Yugashima, revela a onipresença da ideia de sua finitude e angústia diante do desconhecido. A escuridão é vasta e insondável, mas, em meio a ela, seu sentimento é de conforto: "Afinal, o que representa essa paz que experimentamos nas profundezas da escuridão? Seria o sentimento de estarmos ocultos aos olhares dos outros e de nos tornarmos um com a vasta escuridão?" (KAJII, 1974, tradução nossa)

Segundo Dodd (2014), o interesse de Kajii pela escuridão ecoa sua consciência da morte iminente e a presença do tema em sua obra seria uma forma de mitigar sua angústia, até mesmo vê-la sob uma ótica mais positiva, como escreve em uma carta de 1928 após passar um ano em Yugashima sem que seu quadro de saúde melhorasse: 
Um ano se passou, mas, como antes, minhas expectativas não melhoraram. $\mathrm{O}$ corpo deste jovem de vinte e sete anos, que deveria estar passando por uma série de mudanças, está doente. Mas não faço nada, permaneço enfiado em Yugashima. Sinto-me inútil. Sentimentos que emergem em meu coração revelam a inclinação de me precipitar para a morte ao invés da vida. (Falo mais em termos abstratos do que práticos, por isso, não se preocupe). Em minha mente, comecei a repudiar o amor e a procurar me esquivar da coexistência social. Pretendo sentir prazer na escuridão ao invés da luz do sol. (KAJII apud DODD, 2014, p. 25, tradução nossa) ${ }^{6}$

Esse sentimento é repetido em Moscas de Inverno (Fuyu no Hae, 1928), escrito por volta da mesma época. Nele, o narrador expressa seu rancor em relação à luz do sol que lhe promete uma elusiva felicidade. Ele é obrigado a tomar banhos de sol para melhorar a saúde, mas sabe que isso não o salvará. Os únicos seres que se comprazem com o calor e a luz solar são as moscas que habitam seu quarto de enfermo e que ele observa com curiosidade sentado diante da janela. A luz revela aquilo que lhe é negado, uma existência saudável e alegre ao ar livre:

Na última vez em que estive na cidade - pouco antes do solstício de inverno sentia uma infinita tristeza ao contemplar a luz desaparecer da paisagem todos os dias da minha janela. Era invadido por um ressentimento e exasperação negros como nanquim enquanto observava as sombras sepultarem a paisagem. Então, impelido pela angústia de tentar ver o pôr do sol, percorria furiosamente as ruas nas quais sua visão estava sempre obstruída. Agora eu já não tenho mais esse anelo. Não contesto o fato de que uma paisagem ensolarada seja uma representação da felicidade. Mas essa felicidade agora me fere. E isso me deixa ressentido. (KAJII, 1974, tradução nossa)

Com o fôlego curto e o corpo fragilizado, Kajii vive de observar as coisas próximas que transforma em combustível de sua imaginação: pequenas poças de água se transformam em cemitérios de insetos, o fulgor das cerejeiras em flor é alimentado pelos inúmeros cadáveres enterrados sob elas, uma confluência de nuvens no céu azul é um imenso vazio, uma espécie de escuridão em pleno dia.

Se o seu corpo não permite que se mova por longas distâncias e o confina em um quarto, seus olhos o transportam para os topos das árvores e ele é capaz de se sentir como uma de suas folhas oscilando ao vento: “'Ah, que sensação!', pensou ele, 'observar é algo extraordinário. Parte do espírito, ou talvez todo ele, é transferido para aquilo que se observa"” (KAJII, 1974, tradução nossa).

6 Carta de janeiro de 28 de janeiro 1928 in Kajii Motojiro Zenshû. 4 vol. Tokyô Chikuma shobô, 2000. (Na nota de rodapé de Dodd, a carta é mencionada como sendo de 28 de janeiro de 1923, mas acredito que se trate de um erro, pois Kajii vai a Yugashima no final de 1926). 
Seu espírito, da mesma forma, se torna parte da escuridão na qual busca consolo. É para ela que seus personagens, seus alter egos, se voltam em noites insones e é nela que encontram uma espécie de redenção. Depois de tanta angústia e sofrimento, ela the promete um pouco de paz. Em K no Shôten (A Ascensão de K, 1926), o narrador relata como conheceu $\mathrm{K}$, um paciente da clínica de repouso na qual estivera internado, em uma noite de lua cheia. Ele fora caminhar e notou uma silhueta humana na praia. Era K que contemplava a própria sombra projetada na areia pelo luar. Quando o narrador the pergunta a razão de seu comportamento excêntrico, ele explica sua obsessão da seguinte forma:

- Minha imagem começa a ganhar forma. Mas o mais estranho não é isso. À medida que essa imagem se torna mais definida, esse duplo na sombra começa a manifestar uma personalidade própria enquanto eu, o deste mundo, vou me ausentando e, em determinado instante, sinto-me levitar em direção à lua. Não sei como descrever essa sensação, é como se fosse meu espírito. Ele sobe pelos raios de luz emitidos pela lua e, preenchido por uma sensação inefável, ascende aos céus. (KAJII, 1974, tradução nossa)

A ideia do "duplo", doppelgänger, também se repete nos contos de Kajii: sombras que parecem ter vida própria, rostos fantasmagóricos que o observam em espelhos, uma pessoa que desaparece na penumbra diante do protagonista. Essas imagens surgem na convergência da escuridão com uma fonte luminosa como o luar ou uma lâmpada. O que elas representam? Talvez a expectativa do autor, a morte do corpo e a continuidade do espírito que finalmente ascende aos céus como o protagonista sugere que teria ocorrido com $\mathrm{K}$ depois de receber a notícia de que este morrera afogado na mesma praia em que se encontram pela primeira vez.

Em Elogio da Sombra (In Praise of Shadows, 1977) Tanizaki Jun'ichirô exalta o emprego das sombras na estética japonesa. Ele descreve como a arquitetura japonesa, com sua iluminação escassa, desperta um sentimento de reverência e também de temor diante de algo em que tempo e espaço se dissolvem:

A luz do pálido papel de arroz, incapaz de dissipar a intensa escuridão da alcova, é repelida por esta última, criando um universo de confusão no qual escuro e claro são indistinguíveis. Vocês mesmos não notaram uma diferença na luz que ilumina esse tipo de sala, uma rara tranquilidade que não se encontra na iluminação comum? Vocês nunca sentiram uma espécie de medo em face do imutável, o medo de que, nessa sala, vocês poderiam perder totalmente a consciência da passagem do tempo e incontáveis anos passariam até que voltassem a si e se descobrissem velhos e grisalhos? (TANIZAKI, 1977, p. 22, tradução nossa) 
Além de professar seu apreço pelas sombras e pela escuridão, como Tanizaki, Kajii também vê a escuridão como um espaço no qual tempo e espaço estão suspensos. Isso pode ser observado em dois textos nos quais ele repete uma experiência que parece ter ficado em sua memória de forma muito vívida, pois a menciona em dois textos, em Sôkyû (Céu Azul, 1928):

Na noite em questão, caminhava pela estrada sem carregar uma lanterna. Havia uma única casa no meio da estrada, a escuridão era total e a paisagem parecia se resumir à luz que extravasava para o lado de fora pelos nós da madeira da porta. A casa lançava sua luminosidade sobre a estrada. Foi quando de repente vi a silhueta de uma pessoa surgir. Talvez fosse um morador do vilarejo que, como eu, também caminhava sem carregar uma lanterna. Não achei essa silhueta particularmente suspeita ou estranha. Entretanto, por alguma razão, fiquei imóvel enquanto a observava desaparecer em meio à escuridão. A luz em suas costas diminuía e ela se tornava cada vez menos visível. Ela se transformou em uma sensação em minha retina, uma figura da imaginação em meio à obscuridade. Por fim, até mesmo os laços com essa figura da imaginação foram cortados. A ideia de uma escuridão na qual o conceito de lugar não fazia sentido fez com que sentisse um leve estremecimento. Imaginei-me desaparecendo nessa escuridão seguindo essa mesma sequência desesperadora e fui tomado por um temor e uma emoção indescritíveis. (KAJII, 1974, tradução nossa)

E em Yami no Emaki (O Pergaminho ilustrado da Obscuridade, 1930):

Certa noite, percebi que havia um homem caminhando à minha frente, como eu, ele não trazia uma lanterna. Sua figura surgiu de súbito iluminada pela claridade da casa. Ele a deixou atrás de si e seguiu adentrando a escuridão. Eu o observava tomado por uma emoção peculiar. Na verdade, pensei: "Daqui a pouco eu também desaparecerei na escuridão como aquele homem. Se houvesse alguém em pé aqui para me observar, provavelmente me veria desaparecer da mesma forma”. Essa ideia me deixou emocionado, ver a figura daquele homem sumir mexeu comigo. (KAJII, 1974, tradução nossa)

A escuridão engloba os conceitos de vazio, mistério, vastidão, é fácil associála também à ideia de morte. Como esta última, a escuridão também é insondável. Como o homem que caminhava à sua frente, Kajii tem consciência de que também desaparecerá e não consegue conter sua emoção. A figura que desaparece à sua frente é uma representação de si mesmo e da transitoriedade da existência. 


\section{Referências}

DODD, S. The Youth of Things: Life and death in the age of Kajii Motojiro. 1st Edition. Honolulu: University of Hawai'I Press, 2014.

KAJII, M. Remon - Aru kokoro no fûkei: 20 contos. Ôbunsha, 1974. Disponível em https:// www.aozora.gr.jp/index_pages/person74.html Acesso em 24 de Out. 2019.

MISHIMA, Y. Sutegatai shôhin, in Mishima Yuko zenshû, vol. 27, Tôkyo: Shinchôsha, 1975, p. 333.

MORRISON, L. R. Kajii Motojirô, Poet of Darkness. ICU Comparative Culture. No. 46, pp. 185-203, 2014. Disponível em: http://subsites.icu.ac.jp/org/sscc/pdf/morrison_46.pdf Acesso em: 24 de Out. 2019.

MOY, N. O. Kajii Motojirô: an anthology of short Stories translated into English. 1977, 168 f. Master of Arts Thesis, East Asian Languages and Cultures, University of Southern California, Jun 1977. Disponível em: http://digitallibrary.usc.edu/cdm/ref/collection/ p15799coll40/id/41145 Acesso em: 24 de Out. 2019.

NAGAE, N. H. De Katai a Dazai: Apontamentos para uma morfologia do Romance do Eu. Tese de Doutorado, Universidade de São Paulo, 2006. Disponível em: http://www.teses. usp.br/teses/disponiveis/8/8151/tde-14052007-151503/publico/TESE_NEIDE_HISSAE_ NAGAE.pdf Acesso em 24 de Out. 2019.

TANIZAKI, J. In Praise of Shadows. Tradução: Thmas J. Harper e Edward Seidensticker. 1st Edition. Stony Creek: Leete's Island Books, 1977. 